University of Nebraska - Lincoln

DigitalCommons@University of Nebraska - Lincoln

$1-14-2004$

\title{
Inhibition of bovine T lymphocyte responses by extracts of the stomach worm Ostertagia ostertagi
}

M.T. Gómez-Muñoz

A. Canals-Caballero

S. Almeria

P. Pasquali

D.S. Zarlenga

See next page for additional authors

Follow this and additional works at: https://digitalcommons.unl.edu/usdaarsfacpub

This Article is brought to you for free and open access by the U.S. Department of Agriculture: Agricultural Research Service, Lincoln, Nebraska at DigitalCommons@University of Nebraska - Lincoln. It has been accepted for inclusion in Publications from USDA-ARS / UNL Faculty by an authorized administrator of DigitalCommons@University of Nebraska - Lincoln. 
Authors

M.T. Gómez-Muñoz, A. Canals-Caballero, S. Almeria, P. Pasquali, D.S. Zarlenga, and L.C. Gasbarre 


\title{
Inhibition of bovine $\mathrm{T}$ lymphocyte responses by extracts of the stomach worm Ostertagia ostertagi
}

\author{
M.T. Gómez-Muñoz ${ }^{\text {b,* }}$, A. Canals-Caballero ${ }^{c}$, S. Almeria ${ }^{\text {d }}$, \\ P. Pasquali ${ }^{\mathrm{e}}$, D.S. Zarlenga ${ }^{\text {a }}$, L.C. Gasbarre ${ }^{\mathrm{a}}$ \\ a USDA, ARS, ANRI, Immunology and Disease Resistance Laboratory, Beltsville, MD 20705, USA \\ ${ }^{\mathrm{b}}$ Departamento de Atención Sanitaria, Salud Pública y Sanidad Animal, Facultad de Ciencias Experimentales y \\ de la Salud, Universidad Cardenal Herrera-CEU, Edificio Seminario, \\ Avda. Seminario S/N 46113 Moncada, Valencia, Spain

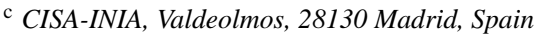 \\ d Dpto. Sanitat i Anatomia Animals. Fac. Veterinaria, Universidad Autónoma de Barcelona, \\ 08193 Bellaterra, Barcelona, Spain \\ e Dipartimento di Sanità Alimentaire ed Animale, Instituto Superiore di Sanita, \\ Viale Regina Elena 299, 00161 Rome, Italy
}

Received 27 June 2003; accepted 14 January 2004

\begin{abstract}
Lowered immune responses during bovine ostertagiosis have been reported in both in vivo and in vitro assay systems. In the present study we have employed three different life cycle stages of the nematode Ostertagia ostertagi to determine if products of this economically important parasite inhibit in vitro proliferation of Con A-stimulated cells from uninfected animals. We have demonstrated an inhibitory effect upon the growth of Con A-stimulated lymphocytes after addition of fourth stage larval (L4) soluble extract (L4SE) to the cultures. In contrast, extracts from the third stage larvae (L3) had little or no inhibitory activity. The suppressive products were also shown to be secreted by the late L4. The suppressive activity is reversible if the L4 products are removed from culture. There is no immediate effect on proliferating cells and the L4SE must be in culture for 24-48 h before suppression is observable. The L4SE caused slight but not statistically significant decreases in the percentage of $\mathrm{T}$ cells and increases in B cell percentages in cultures when compared with cultures stimulated with Con A alone. No changes were seen in percentage of cells positive for markers for CD4, CD8, $\gamma \delta \mathrm{T}$ cells, or monocytes/macrophages as a consequence of the addition of L4SE. In contrast, there was a strong and significant reduction in the expression of the IL-2 receptors in cells cultured in the presence of the worm extract. There was no evidence of either necrosis or apoptosis resulting from the presence of $\mathrm{L} 4$ products in culture. The expression of messenger RNA for interleukin-2, -4, -13, tumor necrosis factor-alpha (TNF- $\alpha$ ), and gamma-interferon ( $\gamma$-IFN)
\end{abstract}

\footnotetext{
* Corresponding author. Tel.: +34-961369000x1223; fax: +34-961395272. E-mail address: mtgomez@uch.ceu.es (M.T. Gómez-Muñoz).
} 
was decreased when L4SE was included in cultures of Con A-stimulated cells compared to cultures stimulated with Con A only. In contrast, messenger RNA expression of transforming growth factor-beta (TGF- $\beta$ ) and interleukin-10 (IL-10) was increased in cells growing in the presence of L4 products. The potential role of these cytokines during ostertagiosis is discussed.

(c) 2004 Elsevier B.V. All rights reserved.

Keywords: Cattle; Bovine; Nematode; Helminth; Immunosuppression; Cytokine

\section{Introduction}

Modulation of the host immune responses by pathogenic organisms, and especially parasites, has been reported on numerous occasions (for review, see Sher et al. (1990, 1992)). Such modulatory activity has been described in both protozoan and nematode infections (Osborne et al., 1996). This ability to lower host responsiveness may induce chronic disease by prolonging the existence of the parasites at the site of infection, or may enhance aspects of the acute infection depending on a variety of factors such as location, host genetics, dose, and molecules secreted by parasites (Urban et al., 1998).

Bovine ostertagiosis is the most economically important parasitic disease affecting cattle in temperate regions of the world. The disease is particularly important in young animals in the first or second grazing season, but adult cattle may also harbor clinical infections. Unlike most gastrointestinal nematodes of cattle, development of immunity against the parasite is slow to arise, and is seldom completely protective against reinfection (Armour, 1985; Ploeger et al., 1995). This prolonged susceptibility to the detrimental effects of the parasite is a principle reason why the parasite causes severe economic losses. It has been postulated by a number of authors that Ostertagia ostertagi is capable of modulating the immune system of the host. Proposed mechanisms have included the generation of suppressor $\mathrm{T}$ cells, a generalized non-specific hyporesponsiveness, and polyclonal lymphocyte activation (Klesius, 1993; Yang et al., 1993; Gasbarre, 1997). In addition, it has been extremely difficult to induce antigen-specific proliferation when adding specific antigens to cultures taken from infected cattle (Cross et al., 1986; Snider et al., 1986).

Studies performed in vivo, including identification of lymphocyte subpopulations in the draining lymph nodes, have shown a decrease in the percentage of CD4+ lymphocytes in non-immune animals after infection (Cross et al., 1986). This coincides with a local increase in IgM-bearing cells and a decrease in CD3+ cells (Almeria et al., 1997b; Gasbarre, 1994). This decrease in the percentage of T cells is seen in spite of a general increase in mRNAs for a number of cytokines including $\gamma$-IFN and IL-4 (Almeria et al., 1997a; Canals et al., 1997).

The ability of $O$. ostertagi antigens to modulate proliferation in Con A-stimulated murine lymphocytes has been demonstrated (Cross and Klesius, 1989). Recently, extracts of $O$. ostertagi larvae have been shown to inhibit in vitro proliferation of bovine lymphocytes from infected cattle (De Marez et al., 1997). Little is known concerning the mechanisms involved in modulation of the immune response to $O$. ostertagi. The purpose of this study was to identify the parasite stages that may modulate host responses, and to clarify the mechanisms involved in suppression. 


\section{Material and methods}

\subsection{Animals and parasite strain}

Holstein-Friesen calves acquired at birth and maintained on concrete to preclude infection were used as sources of peripheral blood mononuclear cells (PBMC). Animals were weaned at 60 days of age and then maintained on a $16 \%$ protein diet supplemented with alfalfa and orchard grass hay, with water available ad libitum. The strain of $O$. ostertagi was isolated at the USDA Regional Parasite Laboratory, Auburn, AL, and has been maintained by transfer through helminth-free calves at 3-6-month intervals, for in excess of 30 years.

\subsection{PBMC isolation and cultures}

Isolation of PBMC was performed over a Ficoll-Hypaque density gradient. Donor animals for all experiments were uninfected calves that had been maintained since birth on concrete. Gradients were centrifuged at $4{ }^{\circ} \mathrm{C}$ for $45 \mathrm{~min}$ at $1000 \times g$. After three washes with Hank's balanced salt solution (HBSS) without calcium and magnesium, the PBMC were resuspended in RPMI supplemented with $5 \times 10^{-5} \mathrm{M}$ 2-mercaptoethanol, $25 \mathrm{mM}$ HEPES, $100 \mathrm{U} \mathrm{ml}^{-1}$ penicillin, $100 \mu \mathrm{g} \mathrm{ml}^{-1}$ streptomycin, $50 \mu \mathrm{g} \mathrm{ml}^{-1}$ kanamycin, and $5 \%$ bovine fetal calf serum (5\% RPMI). Cells were cultured at $4 \times 10^{5}$ cells per microtitre well and Con A was added at 1 or $2.5 \mu \mathrm{g} \mathrm{ml}^{-1}$. Extracts from $O$. ostertagi and other species were added at concentrations ranging from 0 to $50 \mu \mathrm{g} \mathrm{ml}^{-1}$. After 2 or 3 days in culture $\left(37^{\circ} \mathrm{C}, 5 \% \mathrm{CO}_{2}\right)$, $0.5 \mu \mathrm{Ci}$ of tritiated thymidine $\left({ }^{3} \mathrm{H}\right)$ was added to the cultures and cells were harvested $6 \mathrm{~h}$ later onto glass fibre filters for determination of incorporation of ${ }^{3} \mathrm{H}$.

Cells cultured in $62 \mathrm{ml}$ culture flasks at a concentration of $(1-2) \times 10^{6}$ cells ml $^{-1}$ were used for isolation of RNA for cytokine analysis and for staining for the determination of cell surface markers by flow cytometric analysis. Four treatments were used: (1) cells cultured in 5\% RPMI only; (2) lymphocytes cultured with $1 \mu \mathrm{g} \mathrm{ml}^{-1}$ Con A (100\% stimulation); (3) cells cultured with $1 \mu \mathrm{g} \mathrm{ml}^{-1}$ Con A plus $40 \mu \mathrm{g} \mathrm{ml}^{-1}$ of L4 extract; (4) cells cultured with $40 \mu \mathrm{g} \mathrm{ml}^{-1} \mathrm{~L} 4$ extracts. After $18 \mathrm{~h}$ incubation, cells were recovered and washed with HBSS, counted and $5 \times 10^{6}$ cells were removed for flow cytometric analysis. The remaining cells were centrifuged at $200 \times g\left(4^{\circ} \mathrm{C}\right)$ and the pellet was disrupted in guanidinium isothiocyanate, as described below.

\subsection{Parasite extract preparation}

Donor calves were infected with $2 \times 10^{5}$ O. ostertagi L3, and were killed 10 days later to obtain L4 or at later times for recovery of adult worms. Adult and L4 soluble extracts (AdSE, L4SE) were obtained by disruption of the worms followed by centrifugation at $20000 \times g$ at $4{ }^{\circ} \mathrm{C}$. The same procedure was used to obtain SE from other parasite species. Excretory/secretory (ES) products from L4 worms were obtained after $24 \mathrm{~h}$ culture in RPMI containing $1000 \mathrm{U} \mathrm{ml}^{-1}$ penicillin $\mathrm{G}$ potassium, $1 \mathrm{mg} \mathrm{ml}^{-1}$ streptomycin sulfate, and $1 \mu \mathrm{g} \mathrm{ml}^{-1}$ kanamycin (Canals and Gasbarre, 1989). Soluble extract from L3 (L3SE) was obtained from larvae isolated from 14-day-old spaghnum moss cultures. Larvae were 
Table 1

Isotypes and predominant specificity of the monoclonal antibodies used

\begin{tabular}{lll}
\hline Antibody & Isotype & Specificity \\
\hline MM1A & IgGl & CD3 \\
CACT138A & IgGl & CD4 \\
CACT80C & IgG1 & CD8 $\alpha$ \\
CACT116A & IgGl & IL-2R $\alpha$ \\
GD3.8 & IgGl & $\gamma \delta$ T cells \\
BAQ155A & IgGl & B cells \\
CAM36A & IgGl & Monocytes and macrophages \\
\hline
\end{tabular}

subjected to three cycles of freezing and thawing $\left(-20^{\circ} \mathrm{C}\right)$, followed by disruption of the worms in a glass-in-glass homogenizer. The resulting suspension was then centrifuged at $20000 \times g$ at $4{ }^{\circ} \mathrm{C}$. The supernates from the different extracts were dialyzed overnight against PBS using a $10 \mathrm{kDa}$ membrane, filtered through a $2 \mu \mathrm{m}$ pore filter, and kept at $-20{ }^{\circ} \mathrm{C}$ until use (Canals and Gasbarre, 1990). Protein concentration was determined by the method of Bradford (1976).

\subsection{Flow cytometry}

Immunofluorescence staining of PBMC was performed as described by Gasbarre (1994). Monoclonal antibodies (mAb) are described in Table 1. The monoclonal antibody PT85 that recognizes a monomorphic determinant on class I antigens was used as a positive control while background staining levels were determined with control mouse ascitis fluid. After staining, cell staining patterns were determined in an Epics Profile II flow cytometer (Coulter Corp., Hialeah, FL).

\subsection{RNA isolation and competitive reverse transcription-polymerase chain reaction $(R T-P C R)$}

PBMC were disrupted in guanidinium isothiocyanate buffer (4 M guanidinium isothiocyanate, $5 \mathrm{mM}$ Na citrate, $10 \mathrm{mM}$ EDTA, 0.5\% Na sarkosyl, $100 \mathrm{mM}$ 2-mercaptoethanol), and RNA was extracted (Chomczynski and Sacchi, 1987). After RNA isolation, contaminating genomic DNA was digested in the presence of RNAse inhibitors (2.5 U DNAse RNAse-free, $80 \mathrm{U}$ RNAse inhibitor). Synthesis of cDNA was performed using $10 \mu \mathrm{g}$ of total RNA in the presence of oligo dT and Moloney murine leukemia virus RNase H-reverse transcriptase (Superscript Preamplification System, GibcoBRL, Gaithersburg, MD), according to manufacturer's instructions. Detailed description of competitor molecules for bovine IL-2, IL-4, IL-10, IFN- $\gamma$, and TGF $\beta$ have been published elsewhere (Almeria et al., 1997a, 1998; Canals et al., 1997). Competitor molecules for bovine IL-13, and TNF- $\alpha$, were constructed as previously described (Zarlenga et al., 1995). The size of the amplified products as well as the primer sequences are listed in Table 2.

Conditions for polymerase chain reaction were described elsewhere (Canals et al., 1997). Briefly, PCR amplification was performed in a Perkin-Elmer (Perkin-Elmer, Norwalk, CT) 
Table 2

Size (bp) of the cDNA and competitor cytokine molecule fragments amplified, and forward and reverse primer sequences used in the competitive RT-PCR

\begin{tabular}{|c|c|c|c|}
\hline \multirow[t]{2}{*}{ Cytokine and competitor } & \multicolumn{2}{|c|}{ Size (bp) } & \multirow[t]{2}{*}{ Primer } \\
\hline & cDNA & Competitor & \\
\hline IL-2 & 488 & 323 & $\begin{array}{l}\text { GTACAAGATACAACTCTTGTCTTGC }(\mathrm{F}) \\
\text { TCAAGTCATTGTTGTTGAGTAGATGATGCTT }(\mathrm{R})\end{array}$ \\
\hline IL-4 & 400 & 310 & $\begin{array}{l}\text { ATGGGTCTCACCTACCAGCTG }(\mathrm{F}) \\
\text { CAACACTTGGAGTATTTCTCCT }(\mathrm{R})\end{array}$ \\
\hline IFN- $\gamma$ & 440 & 310 & $\begin{array}{l}\text { TATGGCCAGGGCCAATTTTTTAGAGAAATA (F) } \\
\text { TTACGTTGATGCTCTCCGGCCTCGAAAGAG (R) }\end{array}$ \\
\hline TGF- $\beta$ & 608 & 455 & $\begin{array}{l}\text { AGAAGATCTCTGCTGTGTTCGTCAGCTCTAC (F) } \\
\text { CGGAGATCTGAACTGAACCCGTTAATGTCC (R) }\end{array}$ \\
\hline IL-13 & 324 & 273 & $\begin{array}{l}\text { CTGGAATTCATGGCGCTTTTGTTGACCACGG (F) } \\
\text { TACGAATTCGGCCACCTCGATTTTGGTGTC (R) }\end{array}$ \\
\hline TNF- $\alpha$ & 410 & 320 & $\begin{array}{l}\text { AGAATTCAGGTCCTCTTCTCAAGCCTCAAGT }(\mathrm{F}) \\
\text { TGGATCCCGGCAGGTTGATCTCAGCACTGAGG (R) }\end{array}$ \\
\hline IL-10 & 590 & 465 & $\begin{array}{l}\text { ATGCATAGCTCAGCACTACTCTGTTGCCTG (F) } \\
\text { TCACTTTTGCATCTTCGTTGTCATGTAGGTT (R) }\end{array}$ \\
\hline HPRT & 230 & 186 & $\begin{array}{l}\text { GGAGATGATCTCTCAACTTTAACTGG (F) } \\
\text { CATTATAGTCAAGGGCATATCCCAC (R) }\end{array}$ \\
\hline
\end{tabular}

DNA thermal cycler (Gene Amp 9600). Cytokine quantification was done after 35 cycles at $94{ }^{\circ} \mathrm{C}$ for $30 \mathrm{~s}, 55^{\circ} \mathrm{C}$ for $1 \mathrm{~min}$, and $72{ }^{\circ} \mathrm{C}$ for $7 \mathrm{~min}$. PCR was initiated by incubating all reactions for $10 \mathrm{~min}$ at $95^{\circ} \mathrm{C}$ to activate the polymerase (Taq Gold, Perkin-Elmer, Norwalk, CT). cDNA and competitor molecules for each cytokine were differentiated by size separation utilizing a $1.8 \%$ metaphore: $0.2 \%$ GTG agarose gel stained with ethidium bromide. The relative amounts of each cDNA and competitor were quantified by scanning photographed gels, using Sigmagel TM (Jandel Scientific, San Rafael, CA). Amplification of hypoxanthine phosphoribosyltransferase (HPRT) cDNA and competitor molecules was used as a positive control for cDNA synthesis and was normalized to a cDNA:competitor ratio of 1 prior to the amplification of the cytokines. One constant concentration of the competitor molecule was used for each cytokine assay after empirical determination by serial dilutions, so that the amount of amplified products could be quantified (data not shown). Scanned results were expressed as relative intensities of the target cDNA band (A) to its competitor band (B) $(R=A / B)$ and normalized to the amount of HPRT in each sample. Ratios are relative intensity values and do not necessarily reflect fold differences in the amount of cytokine mRNA produced between two analyzed samples.

\subsection{Programed cell death detection}

Genomic DNA was isolated from cells in culture for 3 days utilizing Puregene TM (Gentra system Inc., Minneapolis, MN) according to the manufacturer's instructions. Each sample 
was run in a $1.6 \%$ metaphore:0.07\% GTG gel and then stained with ethidium bromide to visualize DNA laddering for detection of later stages of apoptosis. Cells treated with $5 \%$ ethanol were used as the positive control for apoptosis, while untreated cells stained immediately after isolation from whole blood were used as the negative control.

Annexin $\mathrm{V}$ binding to the externalized phosphatidyl serine of the cell membrane was used to detect the early stages of apoptosis (ApoAlert; Clontech Lab. Inc., Palo Alto, CA). A total of $2 \times 10^{5}$ cells were washed and resuspended in appropriate buffer for the staining, following the manufacturer's instructions. FITC (green fluorescence)-labeled Annexin V and propidium iodide (red fluorescence) were used to distinguish between dead cells and apoptotic cells. Normal cells were not stained, dead cells exhibited both green and red fluorescence, and apoptotic cells showed only green fluorescence.

\subsection{Statistical analysis}

Differences among groups were tested using random effects one-way ANOVA (Jandel Scientific, Sigma, St. Louis, MO). Values were considered to be significantly different when $P \leq 0.05$.

\section{Results}

\subsection{Lymphocyte proliferation}

Lymphocytes cultured for 3 days in the presence of Con A showed high levels of stimulation. The effect of varying concentrations of parasitic extracts taken from the L3, L4, or adult stages on proliferation is shown in Fig. 1. Extracts from the L3 had no inhibitory effect on the magnitude of the Con A-induced proliferation at any concentration tested; moreover there appeared to be slight increases in thymidine incorporation at some of the time points examined. Adult extracts caused a slight decrease in the thymidine incorporation, but this effect was not as marked as that seen for L4 extracts which demonstrated a substantial dose-dependent inhibitory effect on proliferation. This effect was observed with both concentrations of Con A $\left(1\right.$ and $\left.2.5 \mu \mathrm{g} \mathrm{ml}^{-1}\right)$ tested. The effect was first seen at $10 \mu \mathrm{g} \mathrm{ml}^{-1}$ of L4SE in cultures stimulated with $1 \mu \mathrm{g} \mathrm{ml}^{-1}$ Con A, and at $20 \mu \mathrm{g} \mathrm{ml}^{-1}$ of extract at $2.5 \mu \mathrm{g} \mathrm{ml}^{-1}$ Con A. The highest level of suppression was observed between 30 and $40 \mu \mathrm{g} \mathrm{ml}^{-1}$ of L4SE. This effect was not influenced by the source of the PBMC as cells taken from different individual animal did not substantially differ with respect to the level of suppression induced (data not shown). The inhibitory activity was also found in excretory/secretory products of the worm (Fig. 2). Cells cultured in the presence of ESL4 showed 10-30\% less stimulation when compared to cells cultured in similar amounts of soluble extracts from the three life stages of the parasite.

To determine if the extracts could suppress actively dividing cells, PBLs were isolated from an uninfected animal and cultured in the presence of Con A at either 1 or $2.5 \mu \mathrm{g} \mathrm{ml}^{-1}$ with $\operatorname{L} 4 \operatorname{SE}\left(1,10\right.$, and $\left.100 \mu \mathrm{g} \mathrm{ml}^{-1}\right)$ added at 0,1 , or 2 days after culture. The incorporation of ${ }^{3} \mathrm{H}$ was measured at days 2,3 , and 4 in culture. Fig. 3, showing representative results using $1 \mu \mathrm{g} \mathrm{ml}^{-1}$ Con A and $100 \mu \mathrm{g} \mathrm{ml}^{-1} \mathrm{~L} 4 \mathrm{SE}$, indicates that the suppressive effect could 

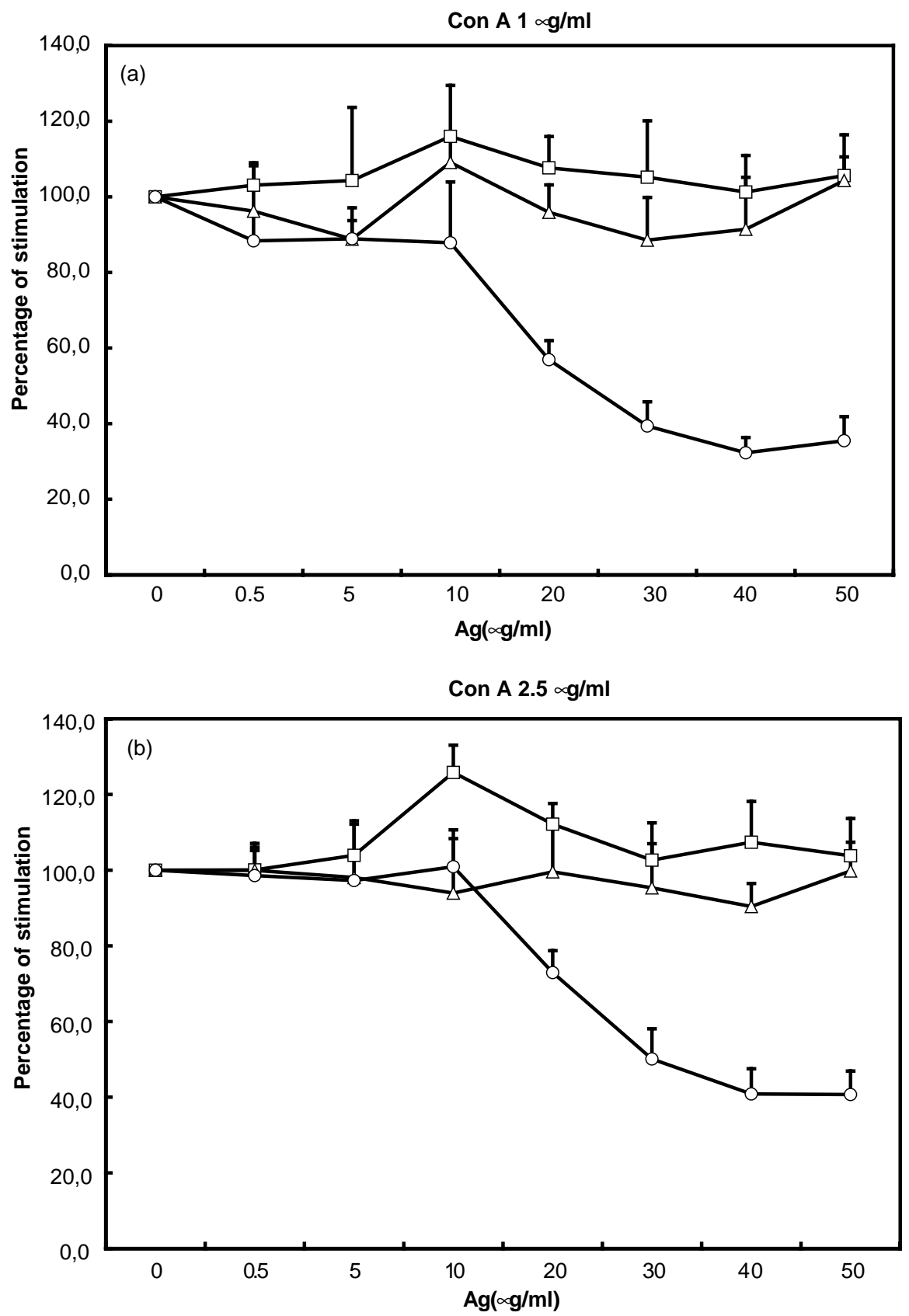

Fig. 1. Percent stimulation of cultured PBLs with $1 \mu \mathrm{g} \mathrm{ml}^{-1}$ (a) or $2.5 \mu \mathrm{g} \mathrm{ml}^{-1}$ (b) of Con A after 3 days in culture with $(\square)$ L3 soluble extract, $(\bigcirc)$ L4 soluble extract, or $(\triangle)$ adult soluble extract. Results are expressed as the mean and standard deviation of four animals. 


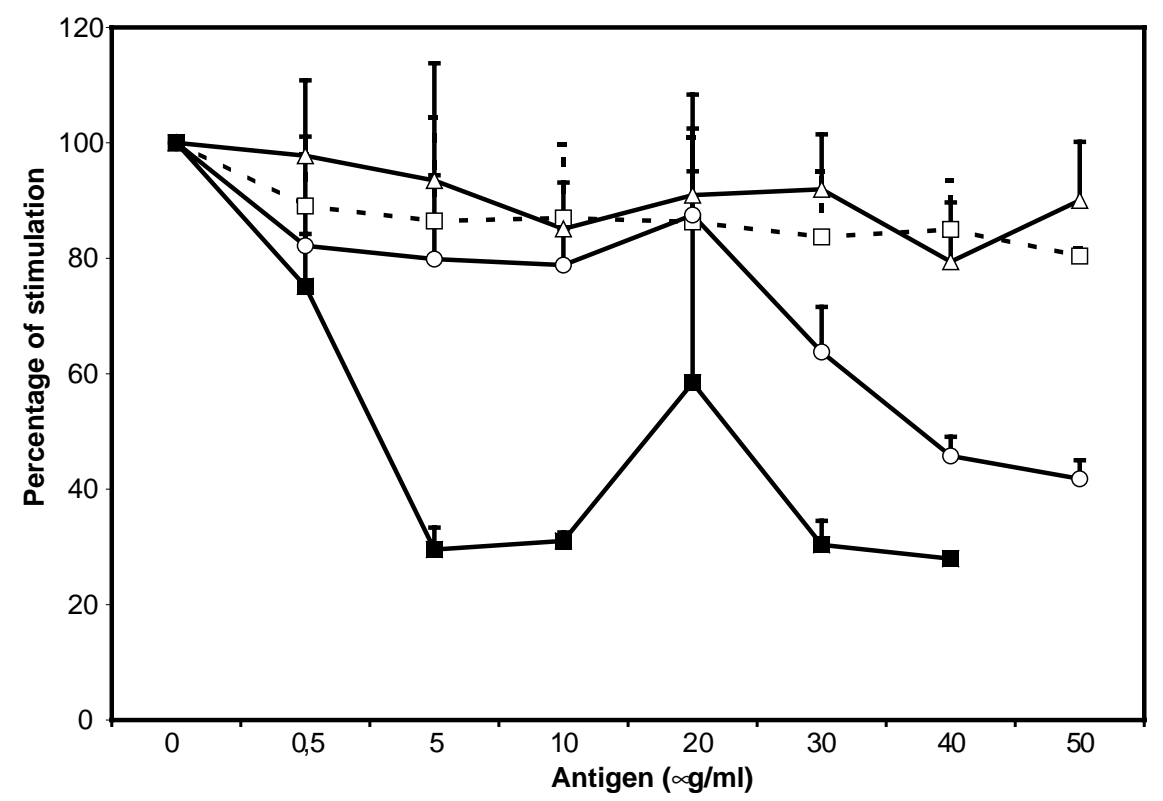

Fig. 2. Percent stimulation of cultured PBLs with $1 \mu \mathrm{g} \mathrm{ml}^{-1}$ of Con A after 3 days in culture with ( $\square$ ) L3 soluble extract, $(\bigcirc)$ L4 soluble extract, $(\triangle)$ adult soluble extract, or $(\square)$ L4 excretory/secretory extract. Results expressed are the mean and standard deviation of samples in triplicate.

not be observed immediately, and that it required at least $48 \mathrm{~h}$ for the effect of the L4SE to be demonstrable on actively dividing cells. To determine if the inhibitory effect was reversible, cells were cultured for 1 day in the presence or absence of $\operatorname{LSEE}\left(1,10\right.$, and $\left.100 \mu \mathrm{g} \mathrm{ml}^{-1}\right)$, then recovered and washed extensively with HBSS, and then subsequently cultured in the presence of Con A $\left(2.5 \mu \mathrm{g} \mathrm{ml}^{-1}\right)$. The incorporation of thymidine was unaffected by previous culture with the parasite extract indicating that the presence of L4SE in culture was required for the observation of the suppressor effect (data not shown).

To determine if extracts of other common nematode parasites of cattle contained a similar inhibitory activity, extracts from adult Cooperia oncophora, Dictyocaulus viviparus, Oesophagostomum radiatum and Haemonchus place $i$ were collected and added to cells cultured with Con A. None of the extracts showed any inhibitory activity at the concentrations tested (0.5-50 $\left.\mathrm{g} \mathrm{ml}^{-1}\right)$ (Fig. 4).

\subsection{Lymphocyte populations affected}

Con A-stimulated cells cultured in the presence of L4SE showed slight reductions in the numbers of cells staining for the CD3, CD4, and CD8 markers when compared to cells stimulated with Con A and cultured in the absence of L4SE. The decreases noted were in the range 10-20\% and, although consistent among cultures, were not statistically significant. Cells staining for surface markers for the $\gamma \delta$ receptor, macrophages, and B 


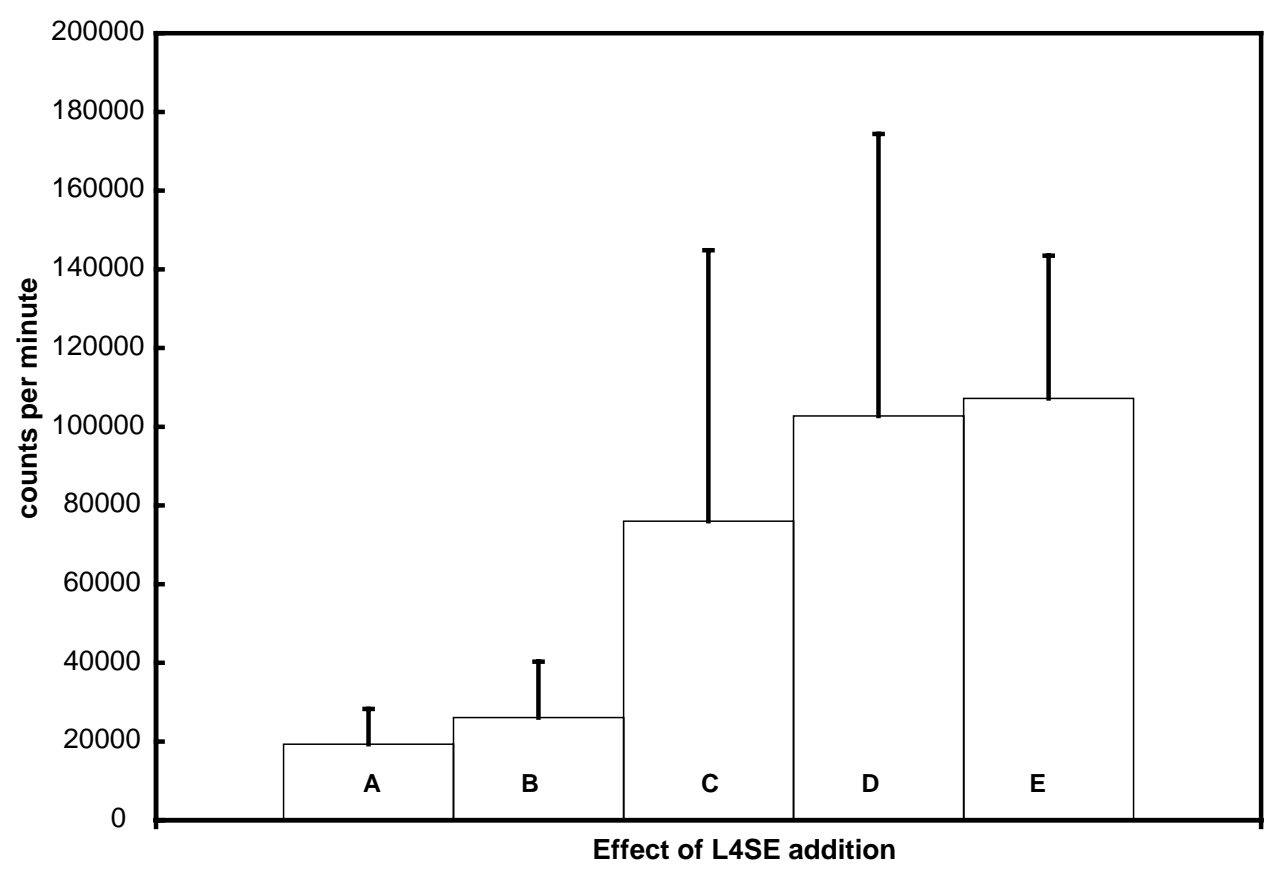

Fig. 3. Effect of addition of L4SE at various time after initiation of culture of PBLs. L4SE at $100 \mu \mathrm{g} \mathrm{ml}{ }^{-1}$ was added at the indicated times to cultures stimulated with Con A at $1 \mu \mathrm{g} \mathrm{ml}^{-1}$ at the time of culture. (A) Non-stimulated cells; (B) L4SE at time of culture; (C) L4SE at day 1 post-culture; (D) L4SE at day 2 post-culture; (E) no L4SE. Results expressed are the mean and standard deviation of samples in triplicate.

cells were unchanged. Together these results indicated a slightly higher, but not statistically significant, percentage of B cells in cultures grown in the presence of L4SE (data not shown).

In contrast to the small differences noted with other surface markers, the percentage of lymphocytes expressing the alpha chain of the IL-2 receptor was significantly reduced in the presence of L4SE. In cultures stimulated with Con A in the absence of L4SE, expression of the IL-2 receptor reached levels as high as $70 \%$ after 1 or 3 days in culture (Fig. 5). In contrast, the addition of larval extracts to the Con A-stimulated cultures resulted in a significant decrease $(P<0.01)$ in the expression of IL-2 receptor by the lymphocytes. A less marked decrease was also seen in IL-2 receptor expression in non-stimulated cultures containing larval extracts.

\subsection{Cytokine gene expression}

To assess cytokine gene expression, mRNA isolated from lymphocytes cultured with mitogen were compared to lymphocytes cultured with the mitogen and L4SE. Cells cultured in the presence of the L4SE showed very low expression for most of the cytokines tested after $18 \mathrm{~h}$ in culture when compared to cells cultured in the presence of the mitogen alone (Table 3). Transcription of IL-2, IL-4, IL-13, TNF- $\alpha$ and IFN- $\gamma$ were much lower in the 


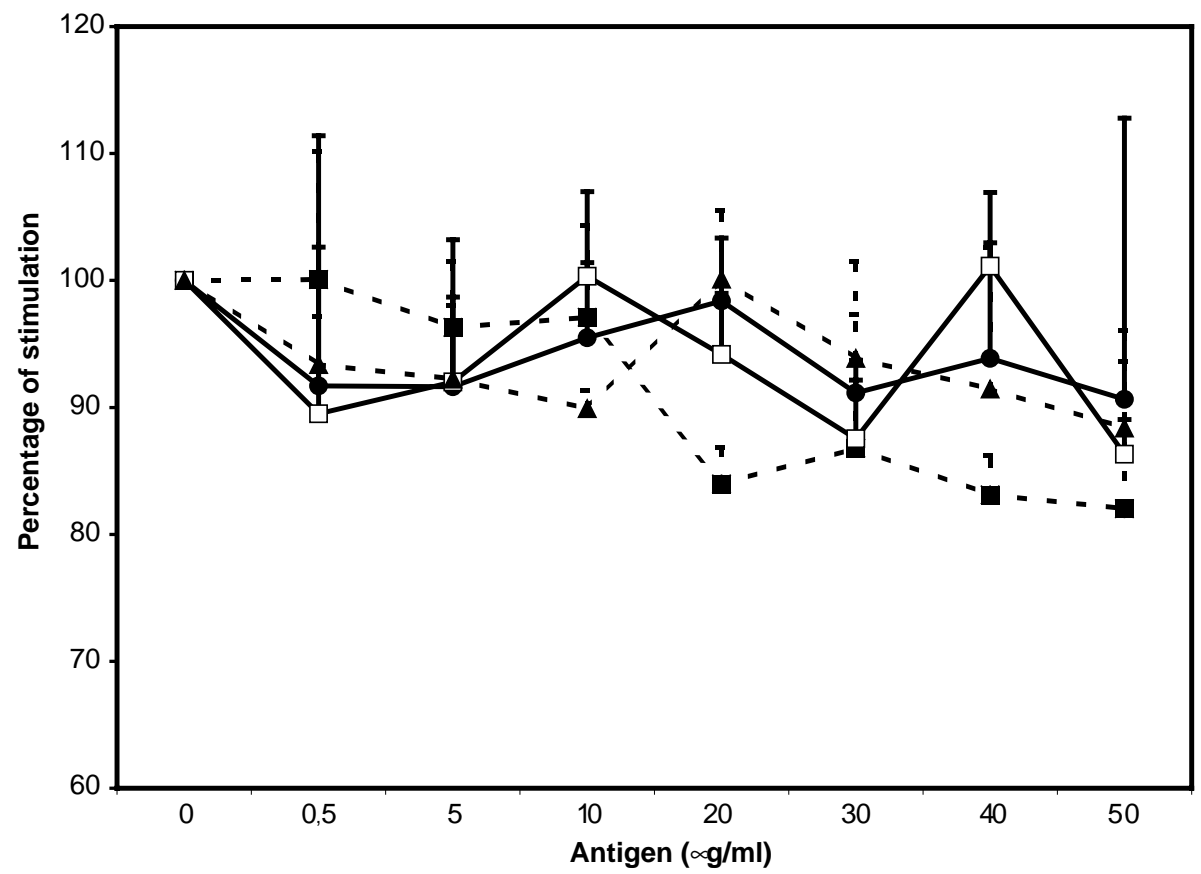

Fig. 4. Percent stimulation of cultured PBLs with $1 \mu \mathrm{g} \mathrm{ml}^{-1}$ of Con A after 3 days in culture. Soluble extract of (ם) O. radiatum, $(\mathbf{\Delta})$ C. oncophora, $(\mathbf{O})$ D. viviparus, and $(\square)$ H. placei. Results expressed are the mean and standard deviation of samples in triplicate.

presence of the L4SE. In contrast, expression of mRNA for TGF- $\beta$ and IL-10 were higher in cells cultured in the presence of the L4SE.

\subsection{Measurement of apoptosis}

The ability of Annexin $\mathrm{V}$ to bind to the external membrane phosphatidyl serine was used to detect cells undergoing programmed cell death. Table 4 shows the percent of apoptotic

Table 3

Expression of mRNA of IL-2, IFN- $\gamma$, IL-4, IL-13, TNF- $\alpha$, TGF- $\beta$ and IL-10 by Con A-stimulated cells in the presence or absence of L4SE

\begin{tabular}{lcl}
\hline Cytokine & Con A at $1 \mu \mathrm{g} \mathrm{ml}^{-1}$ & Con A $+\mathrm{L} 4 \mathrm{SE}$ at $40 \mu \mathrm{g} \mathrm{m} l^{-1}$ \\
\hline $\mathrm{IL}-2$ & 0.9 & 0.1 \\
IFN- $\gamma$ & 20.7 & 1.1 \\
IL-4 & 2.3 & 0.2 \\
IL-13 & 103.1 & 1.6 \\
TNF- $\alpha$ & 1.4 & 0.5 \\
TGF- $\beta$ & 1.4 & 3.1 \\
IL-10 & 0.3 & 0.8
\end{tabular}

Results are the mean of two samples and are expressed as ratios of amplified native cDNA to competitor molecule after normalization to HPRT ratios. 


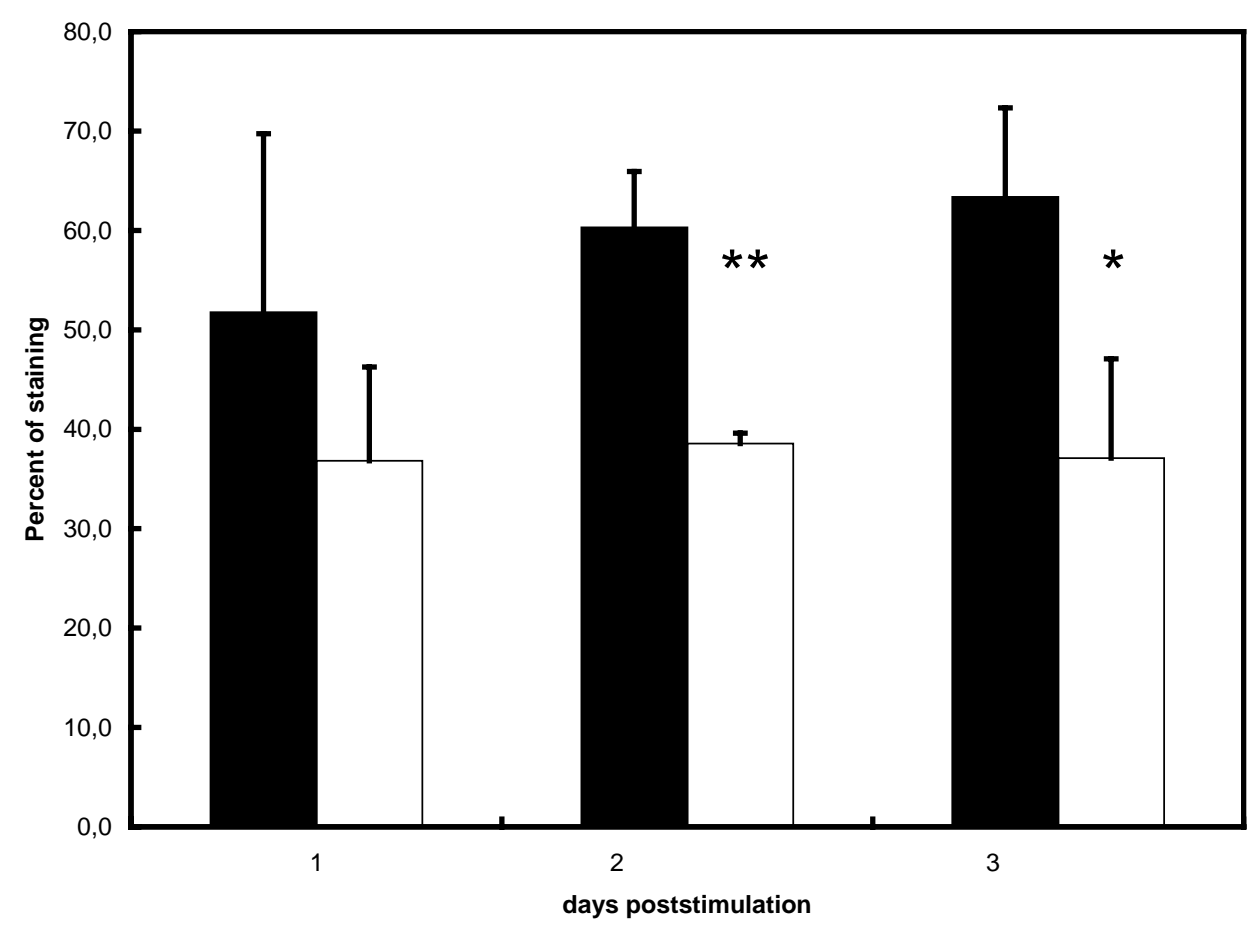

Fig. 5. IL-2R expression in lymphocytes from uninfected animals after stimulation with $1 \mu \mathrm{g} \mathrm{ml}^{-1}$ of Con A in the presence $(\square)$ or absence ( $\square$ ) of L4SE. Results are expressed as the mean and standard deviation of four animals. *Significant differences at $P<0.05 ;{ }^{* *}$ significant differences at $P<0.01$.

cells after different treatments. In the absence of L4SE (treatments 1 and 2) 7-8\% of the cells became apoptotic after $2.5 \mathrm{~h}$ in culture. When cells cultured with L4SE $\left(40 \mu \mathrm{g} \mathrm{ml}^{-1}\right.$; cultures 3 and 4$)$ were examined, a slightly higher staining $(\sim 10 \%)$ was observed. After 1 day, the percentages of stained cells were similar in both Con A cultures $(\sim 16 \%$ in treatments 2 and 3$)$ and in cultures in the absence of Con A $(\sim 20-22 \%$ in treatments 1 and

Table 4

Percent of cells exhibiting Annexin binding after 1, 2, or 3 days in culture in complete medium with or without Con $\mathrm{A}$ at $1 \mu \mathrm{g} \mathrm{ml}^{-1}$ in the presence or absence of L4SE at $40 \mu \mathrm{g} \mathrm{ml}^{-1}$

\begin{tabular}{lrrr}
\hline Treatment & \multicolumn{1}{c}{$2.5 \mathrm{~h}$} & 1 day & 2 days \\
\hline None & $8.0 \pm 1.0$ & $20.8 \pm 2.8$ & $13.5 \pm 3.4$ \\
Con A & $7.2 \pm 1.2$ & $16.2 \pm 2.4$ & $12.4 \pm 2.2$ \\
L4SE & $10.3 \pm 0.6$ & $16.0 \pm 2.4$ & $13.7 \pm 2.2$ \\
Con A + L4SE & $10.5 \pm 2.4$ & $22.3 \pm 4.1$ & $15.7 \pm 2.6$
\end{tabular}

Results expressed as the mean and standard deviation of four animals. 
4), regardless of the presence of L4SE. By the second day in culture the percentage of stained cells was similar among all treatments and no differences were observed in L4SE-treated cultures.

Apoptosis was also measured by directly examining the integrity of the genomic DNA. PBMC from three animals were cultured for 3 days under the four conditions previously noted: in 5\% RPMI, with Con A, with Con A and L4SE, and with L4SE only in the medium. Genomic DNA was extracted and run on agarose gels with positive and a negative controls for analysis, via laddering patterns, for programmed degradation of the DNA. No differences were observed among treatments, and only the positive control clearly showed a laddering pattern (data not shown).

\section{Discussion}

Previous studies have indicated that $O$. ostertagi may suppress in vivo immune responses in cattle. These studies indicated that the parasite causes a depression in $\mathrm{T}$ cell responses while B cells responses remain normal (Klesius, 1993; Snider et al., 1986; Yang et al., 1993). Concurrent with this immunosuppression are increase in the percentage in B cells and $\gamma \delta$ $\mathrm{T}$ cells at the site of infection, i.e. the abomasal mucosa and regional lymph nodes, and a decrease in $\alpha \beta$ T cells (Almeria et al., 1997b; Gasbarre, 1994). A potential mechanism for this suppression is reported in this paper.

Extracts of $O$. ostertagi has usually been examined for the presence of parasite antigens that could be of use in diagnostic tests or as protective immunogens (Canals and Gasbarre, 1990; Klesius, 1993). In the present study, we tested the three parasitic stages of the nematode found within the vertebrate host, for their ability to suppress host immune responses. Crude extracts of L3 were found to possess no inhibitory activity, while extracts of adult worms are weakly suppressive. In contrast, L4 extracts, including excretory-secretory products, are strongly suppressive. It is interesting that the immunosuppression found in vivo in ostertagiosis is transient and is most pronounced during the development from L4 through the early adult stage of the parasite, i.e. from 6 through 20 days post-infection (Klesius, 1993). These results differ slightly from those reported by De Marez et al. (1997) which indicated that adult extracts have a more pronounced suppressive effect. This difference between the two studies in the level of suppression caused by adult extracts may be the result of the strain or age of the parasites used, indicating that different stages or ages of the adult worms should be investigated in future studies.

Programmed cell death is thought to be present in many developmental processes in nematodes as well as in mammals (Driscoll, 1996). In addition, apoptosis is an important component of cytokine-dependent $\mathrm{T}$ cell growth and regulation (Critchfield et al., 1995; Lenardo, 1991). The results of this study do not indicate that L4SE increased the rate of cell death in cultured cells through either necrosis or apoptosis. Although there is no evidence of apoptosis in vitro, this does not rule out the possibility that apoptosis could be an important component of in vivo suppression. Studies have indicated that the induction of apoptosis in immune cell populations is strongly influenced by the microenvironment of the cells (Akbar and Salmon, 1997). As such, further studies are necessary to determine if products of the parasite induce apoptosis in vivo. 
The addition of L4SE to PBL in cultures strongly affected cytokine mRNA expression. In general, mRNA for cytokines involved in cell growth and differentiation were reduced. In contrast, TGF- $\beta$ and IL-10 which are potent down-regulatory cytokines for T cells showed increased expression when the parasite extracts were added to stimulated cells. This is in agreement with the results obtained during experimental infections with the parasite, which showed a decrease in IL- 2 and IFN- $\gamma$ expression after in vitro stimulation of lymphocytes taken from the regional lymph nodes during the early phase of a primary infection (Canals et al., 1997). At the same time messages for IL-4, IL-10 and TGF- $\beta$ increase after a primary exposure to the parasite. In addition, when cytokine mRNA is measured in immune animals, a decrease in IL-4 and TGF- $\beta$ is seen (Almeria et al., 1998). These results point out the central conundrum of $O$. ostertagi infections in cattle. In this host-parasite system, the parasite appears to be highly immunogenic. The lymph nodes draining the site of infection increase in mass 20-30-fold within 3-4 weeks of infection (Gasbarre, 1986). At the same time there is very little infiltrate seen near the L4 while the parasites are in the gastric glands. Immediately after the parasites exit the glands there is a rapid accumulation of host immune cells in the vacated and damaged gland. Thus, it appears that parasite antigens are highly immunogenic in the draining lymph tissues (Gasbarre, 1986), but that the cells either do not successfully home to the site of infection (i.e. the gastric glands) or that they are inactivated by products of the parasite once they reach the developing larvae.

If the parasite can actively suppress reactive cells as they home back to the abomasum, the results demonstrating increases in mRNA expression for only the regulatory cytokines IL-10 and TGF- $\beta$ are intriguing. In extensively studied chronic protozoan infections, such as Trypanosoma cruzi, which does not appear to provoke a protective immune response, it has been postulated that TGF- $\beta$ and IL-10 have a down-regulatory function in the development of immunity, which results in prolonged parasite survival (Gazinelli et al., 1992). Similarly, Leishmania infections have also been shown to induce the production of TGF- $\beta$, both in vivo and in vitro (Barral-Netto et al., 1992; Virmondes Rodrigues et al., 1998). At the same time, TGF- $\beta$ has also been targeted as an antagonist of other protective cytokines during Toxoplasma gondii infections (Hunter et al., 1995). It has been proposed that once induced, TGF- $\beta$ can limit $\mathrm{T}$ cell clonal expansion by acting as an autoregulatory cytokine (Sporn and Roberts, 1990). A potential role for TGF- $\beta$ in $O$. ostertagi infections is especially intriguing because Riddle (1996) has shown that the expression of a TGF- $\beta$ homolog in $C$. elegans is important in hypobiosis, which is perceived to be an important characteristic of trichostrongylid nematodes in general, but is most strongly associated with the biology of $O$. ostertagi infections.

Finally the results of this study emphasize the difficulty in applying the Thl/Th2 paradigm to $O$. ostertagi infections. In murine models a clearly differentiated Th1-Th2 cytokine pattern has been used to explore the immune responses provoked by intracellular and extracellular organisms. This pattern is characterized by an increase in production of IL-2 and IFN- $\gamma$ during a Th1 response against intracellular organisms, and an increase in IL-10 and IL-4, among other cytokines, during a Th2-type response against extracellular parasites, e.g. nematodes. However, this pattern is not always seen, as reported in infections by Trichinella spiralis or Schistosoma mansoni (Pond et al., 1989; Brown et al., 1994). Additionally, in cattle the Th1 versus Th2 commitment is not well defined in either T cell clones or in vivo 
responses (Almeria et al., 1997a; Brown et al., 1994; Canals et al., 1997). Even primary infections by $O$. ostertagi seem to induce very strong Th2 cytokine profiles, i.e. high levels of IL-4. In the well characterized murine model systems, these responses are associated with protective immunity against GI nematodes. In contrast, primary $O$. ostertagi infections induce little or no protective immunity. A possible explanation for this discrepancy may be the suppression of the effector phase of the response in the tissue adjacent to the parasite.

In the present paper, we have shown the presence of suppressive substances in extracts of the L4 stage of $O$. ostertagi, and that the suppressive factor(s) is also present in excretory/secretory products. Although one must be cautious when extrapolating results derived from in vitro studies to the more complex in vivo microenvironment, these data nonetheless suggest that inhibition of local immune responses may be an important facet of the infection, by causing a delay in the generation of protective immune responses. Additional work is required to identify the mechanism of the suppression, and the parasite products responsible. Clarification of the activity will greatly aid efforts to develop effective immunological control programs for this economically important parasite of cattle.

\section{Acknowledgements}

The work of M.T. Gomez-Munoz has been covered by a Postdoctoral Research Grant from the University Complutense of Madrid, Spain. The monoclonal antibody GD3.8 was the generous gift of Dr. Mark Jutila, Montana State University. The authors would like to thank Lisa Davis for her skilful technical assistance.

\section{References}

Akbar, A.N., Salmon, M., 1997. Cellular environments and apoptosis: tissue microenvironments control activated cell death. Immunol. Today 18, 72-76.

Almeria, S., Canals, A., Zarlenga, D., Gasbarre, L.C., 1997a. Quantification of cytokine expression in lamina propria lymphocytes of cattle following infection with Ostertagia ostertagi. J. Parasitol. 83, 1051-1055.

Almeria, S., Canals, A., Zarlenga, D.S., Gasbarre, L.C., 1997b. Isolation and phenotypic characterization of abomasal mucosal lymphocytes in the course of a primary Ostertagia ostertagi infection in calves. Vet. Immunol. Immunopathol. 57, 87-98.

Almeria, S., Canals, A., Gomez-Munoz, M.T., Zarlenga, D.S., Gasbarre, L.C., 1998. Characterization of protective immune responses in local lymphoid tissues after drug attenuated infections with Ostertagia ostertagi in calves. Vet. Parasitol. 80, 53-64.

Armour, J., 1985. The influence of host immunity on the epidemiology of trichostrongyle infections in cattle. Vet. Parasitol. 32, 5-19.

Barral-Netto, M., Barral, A., Brownell, C.E., Skeiky, Y.A., Ellingsworth, L.R., Twardzik, D.R., Reed, S.G., 1992. Transforming growth factor-beta in leishmanial infection: a parasite escape mechanism. Science 257, 545548.

Bradford, M.M., 1976. A rapid and sensitive method for the quantitation of microgram quantities of protein utilizing the principle of protein-dye binding. Ann. Biochem. 72, 248-254.

Brown, W.C., Dacis, W.C., Dobblelaere, A.E., Rice-Ficht, A.C., 1994. CD4+ T-cell clones obtained from cattle chronically infected with Fasciola hepatica and specific for adult worm antigen express both unrestricted and Th2 cytokine profiles. Infect. Immun. 62, 818-827. 
Canals, A., Gasbarre, L.C., 1989. Procedure for the recovery of excretory-secretory products from molting fourthstage: larvae of Ostertagia ostertagi. Proc. Helminthol. Soc. Wash. 56, 201-203.

Canals, A., Gasbarre, L.C., 1990. Ostertagia ostertagi: isolation and partial characterization of somatic and metabolic antigens. Int. J. Parasitol. 20, 1047-1054.

Canals, A., Zarlenga, D.S., Almeria, S., Gasbarre, L.C., 1997. Cytokine profile induced by a primary infection with Ostertagia ostertagi in cattle. Vet. Immunol. Immunopathol. 58, 63-75.

Chomczynski, P., Sacchi, N., 1987. Single-step method of RNA isolation by acid guanidinium thiocyanate-phenolchloroform extraction. Ann. Biochem. 162, 156-159.

Critchfield Jr., M., Boehme, S.A., Lenardo, M.J., 1995. The regulation of antigen-induced apoptosis in mature T lymphocytes. In: Gregory, C.D. (Ed.), Apoptosis and the Immune Response. Wiley, New York, p. 55.

Cross, D.A., Klesius, P.H., Haynes, T.B., 1986. Lymphocyte blastogenesis responses of calves experimentally infected with Ostertagia ostertagi. Vet. Parasitol. 22, 49-55.

Cross, D.A., Klesius, P.H., 1989. Soluble extracts from larval Ostertagia ostertagi modulating immune function. Int. J. Parasitol. 19, 57-61.

De Marez, T., Cox, E., Claerebout, E., Vercruysse, J., Goddeeris, B.M., 1997. Induction and suppression of lymphocyte proliferation by antigen extracts of Ostertagia ostertagi. Vet. Immunol. Immunopathol. 57, 6977.

Driscoll, M., 1996. Cell death in C. elegans: molecular insights into mechanism conserved between nematodes and mammals. Brain Pathol. 6, 411-425.

Gasbarre, L.C., 1986. Limiting dilution analyses for the quantification of cellular immune responses in bovine ostertagiasis. Vet. Parasitol. 20, 133-147.

Gasbarre, L.C., 1994. Ostertagia ostertagi: changes in lymphoid populations in the local lymphoid tissues after primary or secondary infection. Vet. Parasitol. 55, 105-114.

Gasbarre, L.C., 1997. Effects of gastrointestinal nematode infection on the ruminant immune system. Vet. Parasitol. 72, 327-343.

Gazinelli, R.T., Oswald, I.P., Hieny, S., James, S.L., Sher, A., 1992. The microbicidal activity of interferon-gammatreated macrophages against Trypanosoma cruzi involves an L-arginine-dependent, nitrogen oxide-mediated mechanism inhibitable by interleukin-10 and transforming growth factor-beta. Eur. J. Immunol. 22, 2501-2506.

Hunter, C.A., Bermudez, L., Beernink, H., Waegel, W., Remington, J.S., 1995. Transforming growth factor-beta inhibits interleukin-12-induced production of interferon-gamma by natural killer cells: a role for transforming growth factor-beta in the regulation of T cell-independent resistance to Toxoplasma gondii. Eur. J. Immunol. 25, 994-1000.

Klesius, P.H., 1993. Regulation of immunity to Ostertagia ostertagi. Vet. Parasitol. 46, 63-79.

Lenardo, M.J., 1991. Interleukin-2 programs mouse $\alpha \beta$ T lymphocytes for apoptosis. Nature 353, 858-861.

Osborne, J., Hunter, S.J., Devaney, E., 1996. Anti-interleukin-4 modulation of the Th2 polarized response to the parasitic nematode Brugia pahangi. Infect. Immun. 64, 3461-3466.

Ploeger, H.W., Kloosterman, A., Rietveld, F.W., 1995. Acquired immunity against Cooperia spp., Ostertagia spp. in calves: effect of level of exposure and timing of the midsummer increase. Vet. Parasitol. 58, 61-74.

Pond, L., Wassom, D.L., Hayes, C.E., 1989. Evidence for differential induction of helper T-cell subsets during Trichinella spiralis infection. J. Immunol. 143, 4231-4240.

Riddle, D.L., 1996. Control of C. elegans larval development by neuronal expression of a TGF- $\beta$ homolog. Science 274, 1389-1391.

Sher, A., Coffman, R.L., Hieny, S., Scott, P., Cheever, A.W., 1990. Interleukin-5 is required for the blood and tissue eosinophilia but not the granuloma formation induced by infection with Schistosoma mansoni. Proc. Nat. Acad. Sci. U.S.A. 87, 61-69.

Sher, A., Gazinelli, R.T., Oswald, I.P., Clerici, M., Kullberg, M., Pearce, E.J., Berzofsky, J.A., Mossmann, T.R., James, S.L., Morse, H.C., 1992. Role of T-cell derived cytokines in the downregulation of immune responses in parasitic and retroviral infection. Immunol. Rev. 127, 183-204.

Snider, T.G., Williams, J.C., Karns, P.A., Romaire, T.L., Trammel, H.E., Kearney, M.T., 1986. Immunosuppression of lymphocyte blastogenesis in cattle infected with Ostertagia ostertagi and/or Trichostrongylus axei. Vet. Immunol. Immunopathol. 11, 251-264.

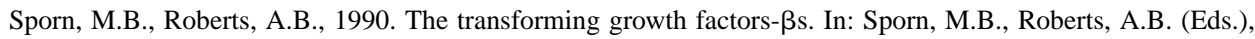
Peptide Growth Factors and their Receptors I. Springer-Verlag, NY, p. 419. 
Urban, J.F., Finkelman, F.D., Donohue, T.S., Gause, W.C., 1998. Cytokine immunomodulation of infectious diseases. In: Kresina, T.F. (Ed.), Immune Modulating Agents. Marcel Dekker, NY, p. 169.

Virmondes Rodrigues, J.R., Santana da Silva, J., Campo-Neto, A., 1998. Transforming growth factor $\beta$ and immunosuppression in experimental visceral leishmaniasis, Infect. Immun. 66, 1233-1236.

Yang, C., Gibbs, H.C., Xiao, L., 1993. Immunologic changes in Ostertagia ostertagi-infected calves treated strategically with an anthelmintic. Am. J. Vet. Res. 54, 1074-1083.

Zarlenga, D.S., Canals, A., Gasbarre, L.C., 1995. Method for constructing internal standards for use in competitive PCR. Biotechniques 19, 324-326. 